\title{
Comparison of the iCare rebound tonometer and the Goldmann applanation tonometer
}

\author{
FENG GAO, XU LIU, QING ZHAO and YINGZHE PAN \\ Department of Ophthalmology, The First People's Hospital of Xiangyang, \\ Hubei University of Medicine, Xiangyang, Hubei 441000, P.R. China
}

Received January 18, 2016; Accepted February 2, 2017

DOI: $10.3892 /$ etm.2017.4164

\begin{abstract}
Tonometry is a fundamental procedure in routine ophthalmologic examination. Although regarded as the reference standard, the Goldmann applanation tonometer (GAT) has its limitations. A new portable alternative to the GAT is the iCare rebound tonometer (RT). The aim of the present study was to compare the intraocular pressure (IOP) results obtained using the RT and GAT and then correlate the results with the central corneal thickness (CCT). Moreover, the tolerability and safety of the RT were evaluated. The IOP of 336 patients (672 eyes) was determined by the RT and GAT. The patients were divided into three groups (group A, 7-15 mmHg, $\mathrm{n}=74$; group $\mathrm{B}, 16-22 \mathrm{mmHg}, \mathrm{n}=218$; and group $\mathrm{C}, 23-50 \mathrm{mmHg}, \mathrm{n}=44$ ), based on the GAT IOP readings. Pachymetry and slit lamp inspection were also performed. To establish an agreement between the devices, a Bland-Altman analysis and paired t-test were performed. The correlation between CCT and IOP readings obtained by the two devices were assessed using linear regression correlation analysis. The mean IOP values of the RT and the GAT were $18.30 \pm 5.10$ and $18.52 \pm 4.46 \mathrm{mmHg}$, respectively. There were no significant differences between them $(\mathrm{t}=-1.31$, $\mathrm{P}=0.19)$. The $95 \%$ confidence interval of the differences between the two devices was -5.80-6.24 mmHg. The RT readings are correlated well with those of GAT $(r=0.806$, $\mathrm{P}=0.001)$. However, the RT measurements were significantly $(\mathrm{t}=-2.84, \mathrm{P}=0.007)$ lower $(-1.66 \pm 3.87 \mathrm{mmHg})$ than those obtained with GAT when GAT $\geq 23 \mathrm{mmHg}$. Both the RT $(r=0.390, P=0.001)$ and the GAT $(r=0.191, P=0.001)$ showed positive correlations with CCT. The IOP measurement with RT was well tolerated. None of the corneal epithelial defects was detected and all subjects denied discomfort.
\end{abstract}

Correspondence to: Yingzhe Pan, Department of Ophthalmology, The First People's Hospital of Xiangyang, Hubei University of Medicine, 15 Jiefang Road, Xiangyang, Hubei 441000, P.R. China E-mail: panyz827@163.com

Key words: iCare rebound tonometer, Goldmann applanation tonometry, intraocular pressure, central corneal thickness
The RT is well tolerated and safe, and can be considered a reliable alternative to GAT for patients in a low to moderate IOP range. However, in patients with high IOP values, the measurements obtained with RT did not correlate well with those obtained by GAT. The RT readings are influenced more by CCT compared to GAT.

\section{Introduction}

Tonometry is a fundamental procedure in routine ophthalmologic examination. Accurate measurements of intraocular pressure (IOP) are key to diagnosing and monitoring glaucoma (1-4). The Goldmann applanation tonometer (GAT) is regarded as the reference standard in tonometry in current clinical practice (5). The GAT uses a small probe to gently flatten a part of the cornea to measure eye pressure and a microscope known as a slit lamp to examine the eye. The pressure in the eye is measured by the amount of force required to flatten the cornea. This type of tonometry is extremely accurate and is often used to measure IOP after a simple screening test. The iCare rebound tonometer (RT) is a new type of portable tonometer. It calculates IOP by measuring the motion parametric variation after the probe strikes the cornea. Compared with the GAT, the RT is handy, convenient and independent from other equipment.

In the present study, the two tonometers were compared to assess the reliability of applying RT in clinical procedures.

\section{Patients and methods}

General information. In total, 336 patients (672 eyes) from the Department of Ophthalmology, the First People's Hospital of Xiangyang (Hubei, China) from January 2013 to October 2013 were recruited to participate in this study. There were 151 males and 185 females whose ages ranged from 23 to 81, with an average age of 53 years. The patients were diagnosed with glaucoma and suspected glaucoma (150 patients), ametropia (91 patients) and other eye diseases (95 patients). Patients with corneal cicatrix, corneal edema and corneal refractive surgeries as well as those with corneal astigmatism $\geq 3 \mathrm{D}$ were excluded from the study. Ratified by the Ethics Committee of the hospital, all the subjects were informed of the purpose and process of this study, and signed informed consents before the examination. 
Major measuring equipment. The Goldmann AT 900 applanation tonometer (Hagg-Streit AG, Koeniz, Switzerland); iCare TA01i rebound tonometer (Tiolat Oy, Helsinki, Finland); and the DGH Pachette 3 cornea thickness meter (DGH Technology Inc., Exton, PA, USA) were used to conduct this study.

\section{Methods}

Tonometry. To obtain the IOP reading using the RT, the one-off probe was changed for each reading and the patient was required to be seated, staring straight ahead at the 0.05 sighting mark within a distance of 5 meters. The frontal support bar was adjusted to position the probe at the same height as the corneal vertex at about $4-8 \mathrm{~mm}$. The probe was vertical to the central corneal plane. After obtaining six successful measurements by continuous measurements, the iCare analyzes the data automatically and displays the IOP. Based on the standard deviation of the measurements, the tonometer showed 4 types of error bars - null, low, medium and high. This study only recorded IOP results with null error bar; otherwise, another measurement would be implemented.

To obtain the IOP reading using the GAT, the patient was seated and was required to stare at the 0.05 sighting mark within a distance of 5 meters. According to conventional methods, the eyelid margins and eyelashes could not be touched when the head was pressed, and the eyeball should not receive any external pressure when lightly lifting the upper eyelid during the measurement. The reading was carried out three times and if the difference value was within $\pm 1 \mathrm{mmHg}$, the medium value was recorded as the result of this IOP measurement.

When measuring the IOP, the RT and GAT were operated by Q. Zhao and F. Gao, respectively. Considering that the eyeball massage effect occurring during the examination would lower the IOP, every patient was tested with the RT first. The doctor who operated the GAT had no knowledge of the RT measurements before each examination. The measurements of two tonometers were completed within $10 \mathrm{~min}$. During the examination, the right eye was tested first and then the left. Only the measured values of the right eyes were used to conduct the statistical analysis.

The RT tolerance and security measurement using the visual analog scale (VAS) was used to evaluate the degree of comfort during the examination. Patients were required to mark the comfort level of the RT measurement in a calibrated line segment with one end (0) referring to pain while the other end (10) referring to comfort in order to quantitate the record results. After the RT measurement, the corneal fluorescein dye was inspected under the slit lamp and used to record the integrity of the patients' corneal epithelium.

Central corneal thickness (CCT) measurement. The central part of the pupil was selected to locate the central cornea. After measuring for five times, the minimum value was recorded as the result.

Statistical method. The SPSS 17.0 statistical software (Chicago, IL, USA) was used to conduct the statistical analysis. The measured data in this study are shown as mean \pm SD. According to the K-S verification, the IOP values measured by the RT and GAT conformed to the normal distribution. The
Table I. Measured IOP values of RT and GAT.

\begin{tabular}{lccc}
\hline & $\mathrm{RT}(\mathrm{mmHg})$ & $\mathrm{GAT}(\mathrm{mmHg})$ & $\Delta \mathrm{IOP}(\mathrm{mmHg})$ \\
\hline Mean \pm SD & $18.30 \pm 5.10$ & $18.52 \pm 4.46$ & $-0.22 \pm 3.07$ \\
Range & $8-43$ & $9-44$ & $-11-9$ \\
$95 \% \mathrm{CI}$ & $8.30-28.30$ & $9.78-27.26$ & $-5.80-6.24$ \\
\hline
\end{tabular}

$\triangle \mathrm{IOP}=\mathrm{RT}-\mathrm{GAT}$. IOP, intraocular pressure; RT, rebound tonometer; GAT, Goldmann applanation tonometer; CI, confidence interval.

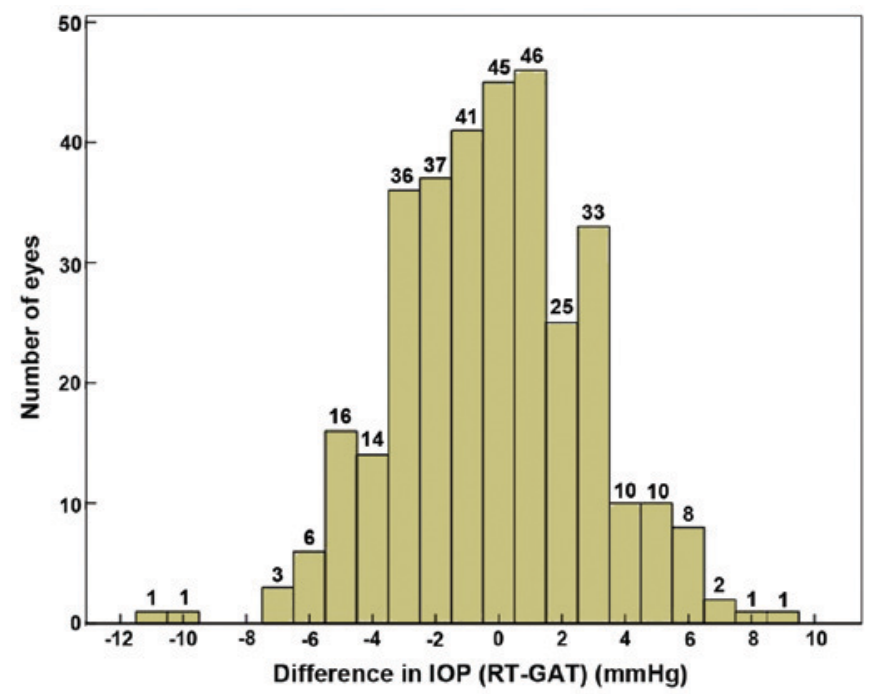

Figure 1. Distribution histogram of the difference in IOP (RT - GAT) IOP, intraocular pressure; RT, rebound tonometer; GAT, Goldmann applanation tonometer.

consistency of the RT and GAT measurements were analyzed by Bland-Altman with a paired t-test to indicate the differences between the two. The correlation among the RT, GAT and CCT were assessed with the Pearson linear regression correlation analysis. $\mathrm{P}<0.05$ indicates a statistical significance.

\section{Results}

Consistency of the RT and GAT measurements. The average IOP value of the 336 right eyes measured by the RT and GAT were $18.30 \pm 5.10$ and $18.52 \pm 4.46 \mathrm{mmHg}$, respectively. The RT readings were relatively lower than those obtained by GAT. However, their difference had no statistical significance $(\mathrm{t}=-1.31, \mathrm{P}=0.19)$ (Table I). As shown by the linear regression analysis, the measurements of the two tonometers had a significant correlation $(\mathrm{r}=0.806, \mathrm{P}=0.001)$. The measurement difference of the tested 263 eyes $(78.3 \%$ ) was $\leq \pm 3 \mathrm{mmHg}$, with its distribution shown in Fig. 1. The Bland-Altman diagram showed that the difference value between the RT and GAT measurements was $-0.22 \pm 3.07 \mathrm{mmHg}$, with a $95 \%$ confidence interval (CI) of -5.80-6.24 mmHg (Fig. 2).

According to the IOP value measured by GAT and ISO 8612 (6), tested patients were classified into three groups: group A, 7-15 mmHg, $\mathrm{n}=74$; group $\mathrm{B}, 16-22 \mathrm{mmHg}, \mathrm{n}=218$; and group $\mathrm{C}, 23-50 \mathrm{mmHg}, \mathrm{n}=44$. As shown by the group comparison (Table II), when GAT measurement fell into the range of 
Table II. RT and GAT measured values of three different IOP groups.

\begin{tabular}{|c|c|c|c|c|c|c|}
\hline & \multicolumn{2}{|c|}{$\begin{array}{c}\text { Group A } \\
\text { (IOP 7-15 mmHg, } \mathrm{m}=74 \text { ) }\end{array}$} & \multicolumn{2}{|c|}{$\begin{array}{c}\text { Group B } \\
(\text { IOP } 16-22 \mathrm{mmHg}, \mathrm{n}=218)\end{array}$} & \multicolumn{2}{|c|}{$\begin{array}{c}\text { Group C } \\
\text { (IOP } 23-50 \mathrm{mmHg}, \mathrm{n}=44 \text { ) }\end{array}$} \\
\hline & RT & GAT & RT & GAT & RT & GAT \\
\hline Mean \pm SD & $13.28 \pm 3.09$ & $13.41 \pm 1.60$ & $18.64 \pm 3.58$ & $18.60 \pm 1.85$ & $25.07 \pm 5.54$ & $26.73 \pm 4.44$ \\
\hline Range & $8-20$ & 9-15 & $11-31$ & 16-12 & $15-43$ & $23-44$ \\
\hline $\begin{array}{l}\Delta \mathrm{IOP}(\mathrm{mmHg}) \\
(\text { mean } \pm \mathrm{SD})\end{array}$ & \multicolumn{2}{|c|}{$\begin{array}{c}-0.12 \pm 2.77 \\
(\mathrm{t}=-0.38, \mathrm{P}=0.71)\end{array}$} & \multicolumn{2}{|c|}{$\begin{array}{c}0.04 \pm 2.86 \\
(\mathrm{t}=0.21, \mathrm{P}=0.83)\end{array}$} & \multicolumn{2}{|c|}{$\begin{array}{c}-1.66 \pm 3.87 \\
(\mathrm{t}=-2.84, \mathrm{P}=0.007)\end{array}$} \\
\hline $95 \% \mathrm{CI}$ & \multicolumn{2}{|c|}{$-5.66-5.42$} & \multicolumn{2}{|c|}{$-5.57-5.65$} & \multicolumn{2}{|c|}{$-9.25-5.93$} \\
\hline$\Delta \mathrm{IOP} \leq \pm 3 \mathrm{mmHg}^{\mathrm{a}}$ & \multicolumn{2}{|c|}{$83.7 \%$} & \multicolumn{2}{|c|}{$79.8 \%$} & \multicolumn{2}{|c|}{$61.4 \%$} \\
\hline$\Delta \mathrm{IOP}> \pm 5 \mathrm{mmHg}^{\mathrm{b}}$ & \multicolumn{2}{|c|}{$2.7 \%$} & \multicolumn{2}{|c|}{$5.5 \%$} & \multicolumn{2}{|c|}{$22.7 \%$} \\
\hline
\end{tabular}

$\Delta \mathrm{IOP}=\mathrm{RT}-\mathrm{GAT}$. ${ }^{\mathrm{a}}$ The percentage of the difference between RT and GAT measured IOP values is with $\pm 3 \mathrm{mmHg}$. ${ }^{\mathrm{b}} \mathrm{The}$ percentage of the difference between RT and GAT measured IOP values is more than $\pm 5 \mathrm{mmHg}$. RT, rebound tonometer; GAT, Goldmann applanation tonometer; IOP, intraocular pressure; CI, confidence interval.

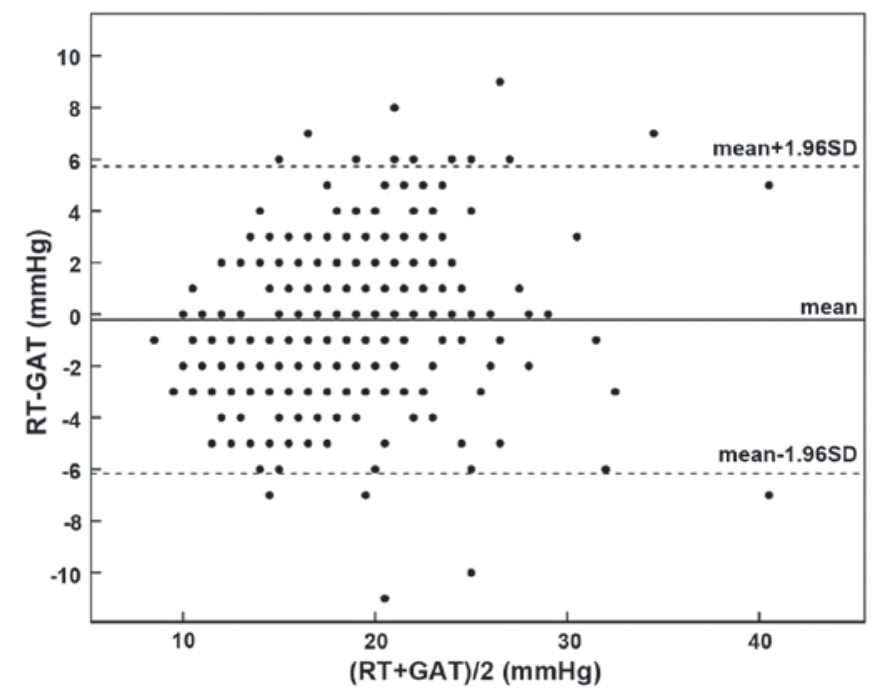

Figure 2. Difference of the RT and GAT measurements analyzed by Bland-Altman. RT, rebound tonometer; GAT, Goldmann applanation tonometer.

7-15 and 16-22 $\mathrm{mmHg}$, the difference of the IOP value measured by the RT and the GAT was quite small and of no statistical significance, which were $-0.12 \pm 2.77$ and $0.04 \pm 2.86 \mathrm{mmHg}$, respectively. However, when the GAT reading was $\geq 23 \mathrm{mmHg}$, the RT measurement $-1.66 \pm 3.87 \mathrm{mmHg}$ was significantly lower than those obtained with the GAT. The difference was statistically significant $(\mathrm{t}=-2.84, \mathrm{P}=0.007)$. Moreover, 95\% CI $(-9.25-5.93)$ of the difference increased significantly. The measurement difference of 206 eyes $(61.4 \%)$ was $\leq \pm 3 \mathrm{mmHg}$ while that of 76 eyes $(22.7 \%)$ was $> \pm 5 \mathrm{mmHg}$.

Correlation between the RT and GAT measured values and $C C T$. The linear regression analysis showed that the RT $(\mathrm{r}=0.390, \mathrm{P}=0.001)$ and the GAT $(\mathrm{r}=0.191, \mathrm{P}=0.001)$ showed a positive correlation with CCT. The impact of CCT on the RT was stronger than that following GAT. The equation of linear regression was $\mathrm{RT}=-10.67+0.053 \times \mathrm{CCT}$ and

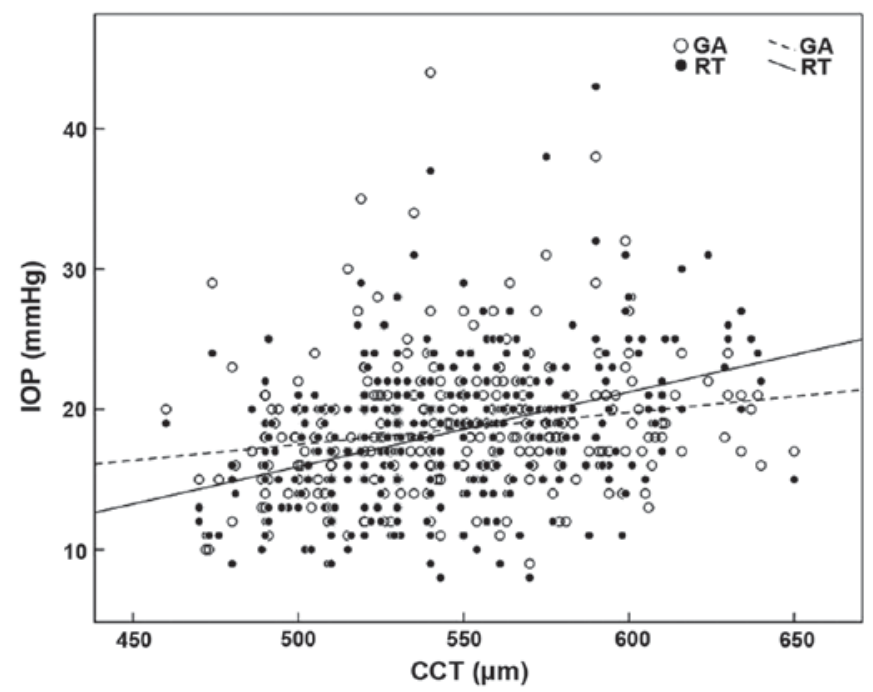

Figure 3. Scatter diagram of the correlation between the CCT and IOP values measured with the RT and the GAT. CCT, central corneal thickness; IOP, intraocular pressure; RT, rebound tonometer; GAT, Goldmann applanation tonometer.

GAT $=6.10+0.023 \times$ CCT, respectively. The scatter diagram is shown in Fig. 3.

Security and endurance of the RT. After the RT measurement, no corneal epithelial defect was detected among the 336 tested patients. All the subjects denied discomfort with the average VAS of $9.82 \pm 1.05$.

\section{Discussion}

Tonometry is a fundamental procedure in routine ophthalmologic examination. IOP is especially important for treating glaucoma. Although intraocular hypertension is not a requirement, it is still a significant risk factor in the development of glaucoma treatment $(7,8)$. Lowering the IOP level is also the only effective treatment means to control the development of glaucoma in clinical practices. Therefore, accurately 
measuring IOP is crucial when diagnosing and monitoring glaucoma.

The anterior chamber cannula technique is the most accurate method to measure IOP directly (9). However, it is an invasive operation, as this method can only be applied in experimental research (10). In clinical applications, GAT is recognized as the global reference standard of tonometry (11-14). With relatively high accuracy, the GAT has become a standard to test the reliability of other tonometers in clinical applications. The iCare RT invented by Kontiola is a new type of portable tonometer, which calculates the tonometer through magnetic induction and records velocity change after the probe strikes the cornea (15-17). The RT measurement shows relatively high accuracy in rats and other animals. However, few studies with large sample size have been conducted concerning its clinical application.

This study, in which patients who had cornea-related diseases are removed, investigates 336 patients by using the GAT and the RT to measure IOP. The comparison shows that the results of two tonometers have a significant correlation $(\mathrm{r}=0.806, \mathrm{P}=0.001)$, and the RT measurements are a little lower than those obtained with GAT $(-0.22 \pm 3.07 \mathrm{mmHg})$ and have no statistical significance $(\mathrm{t}=-1.31, \mathrm{P}=0.19)$. The Bland-Altman diagram shows that a $95 \% \mathrm{CI}$ of the difference value is $-5.80-6.24 \mathrm{mmHg}$ and the difference value of 263 eyes $(78.3 \%) \leq \pm 3 \mathrm{mmHg}$, which is similar to Iliev et al (18) study of $95 \% \mathrm{CI}-3.2-5.2 \mathrm{mmHg}$ and difference value $\leq \pm 3 \mathrm{mmHg}$. All of these results indicate high consistency between the RT and the GAT.

When the tested eyes are further grouped with the IOP results obtained with the GAT, the results show that in the normal IOP range of 7-22 $\mathrm{mmHg}$, the RT measurements are consistent with the overall results. However, in the high IOP values $(23-50 \mathrm{mmHg})$, there is a significant difference between the $\mathrm{RT}$ and the GAT readings with the average of $-1.66 \mathrm{mmHg}$ $(\mathrm{t}=-2.84, \mathrm{P}=0.007)$. However, this difference may not be of great significance in clinical practice (19). Considering that the discrete parameter SD (3.87) and 95\% CI (-9.25-5.93) are on the increase, we still think that we should be cautious in the clinical application since the measurement with the RT does not correlate well with the GAT in high IOP values.

Many studies $(20,10)$ show that the GAT readings are influenced by CCT. When the corneal thickness increases by $10 \mu \mathrm{m}$, the GAT readings will increase by about $0.2 \mathrm{mmHg}$ accordingly. This study verifies the results that we obtained while conducting this research. The linear regression equation of the GAT and the CCT are GAT=6.10+0.023 x CCT ( $\mathrm{r}=0.191$, $\mathrm{P}=0.001)$. Moreover, the RT shows a positive correlation with the CCT (RT=-10.67+0.053 x CCT; $\mathrm{r}=0.390, \mathrm{P}=0.001)$. When the CCT increases by $10 \mu \mathrm{m}$, the RT readings will increase by about $0.5 \mathrm{mmHg}$. Besides, as the RT has a higher correlation coefficient than that of the GAT, the RT readings are influenced more by the CCT compared to the GAT. However, some studies $(21,22)$ consider that the corneal biomechanical property including the corneal hysteresis $(\mathrm{CH})$ and the corneal resistance factor (CRF) impose more influence on the IOP. Thus, the multivariate regression analysis is much more suitable to uncover and interpret the correlation among the IOP and CCT, and $\mathrm{CH}$ and CRF. The weaker correlation coefficient between the GAT, RT and CCT is shown in this study.
The RT probe weighs about $24 \mathrm{mg}$, and the radius of the plastic head end that contacts the cornea is about $0.9 \mathrm{~mm}$. The speed of the probe striking the cornea is about $0.25-0.35 \mathrm{~m} / \mathrm{sec}$ which is faster than a blink reflex. All these characteristics enable the RT measurement to be quick and comfortable. When compared with the GAT, the advantages of the RT measurement can be best reflected in patients who are disabled, have poor coordination, and those with corneal cicatrix (23).

In conclusion, the RT is well tolerated and safe, and is a reliable alternative to the GAT in patients with a low to moderate IOP range. However, in patients with high IOP values, the measurements obtained with RT do not correlate well with the GAT. The RT readings are influenced more by the CCT compared to the GAT. Beside, further investigations should be conducted to discuss the influence of corneal biomechanical properties with the GAT and RT measurements.

\section{References}

1. Tamburrelli FC, Genitiempo M, Bochicchio M, Donisi L and Ratto C: Cauda equina syndrome: evaluation of the clinical outcome. Eur Rev Med Pharmacol Sci 18: 1098-1105, 2014.

2. Zicari AM, Rugiano A, Ragusa G, Savastano V, Bertin S, Vittori $\mathrm{T}$ and Duse M: The evaluation of adenoid hypertrophy and obstruction grading based on rhinomanometry after nasal decongestant test in children. Eur Rev Med Pharmacol Sci 17: 2962-2967, 2013.

3. Portincasa P, Moschetta A, Giampaolo M and Palasciano G: Diffuse gastrointestinal dysmotility by ultrasonography, manometry and breath tests in colonic inertia. Eur Rev Med Pharmacol Sci 4: 81-87, 2000.

4. Jiang SP and Huang LW: Role of gastroesophageal reflux disease in asthmatic patients. Eur Rev Med Pharmacol Sci 9: 151-160, 2005.

5. Kass MA: Standardizing the measurement of intraocular pressure for clinical research. Guidelines from the Eye Care Technology Forum. Ophthalmology 103: 183-185, 1996.

6. Internationaler Standard für Augentonometer ISO 8612. Beuth-Verlag GmbH, Berlin, 2001 (In German).

7. Hu J, Bui KM, Patel KH, Kim H, Arruda JA, Wilensky JT and Vajaranant TS: Effect of hemodialysis on intraocular pressure and ocular perfusion pressure. JAMA Ophthalmol 131: 1525-1531, 2013.

8. Vyas P, Naik U and Gangaiah JB: Efficacy of bimatoprost $0.03 \%$ in reducing intraocular pressure in patients with $360^{\circ}$ synechial angle-closure glaucoma: a preliminary study. Indian J Ophthalmol 59: 13-16, 2011.

9. Matsuura K, Suto C, Akura J and Inoue Y: Bag and chamber flushing: a new method of using intracameral moxifloxacin to irrigate the anterior chamber and the area behind the intraocular lens. Graefes Arch Clin Exp Ophthalmol 251: 81-87, 2013.

10. Kohlhaas M, Boehm AG, Spoerl E, Pürsten A, Grein HJ and Pillunat LE: Effect of central corneal thickness, corneal curvature, and axial length on applanation tonometry. Arch Ophthalmol 124: 471-476, 2006.

11. Eldaly MA: Goldmann versus disposable applanation tonometer tips in glaucoma patients and normal subjects. Curr Eye Res: Aug 19,2015 (Epub ahead of print).

12. Tamçelik N, Atalay E, Cicik E and Özkök A: Comparability of Icare pro rebound tonometer with Goldmann applanation and noncontact tonometer in a wide range of intraocular pressure and central corneal thickness. Ophthalmic Res 54: 18-25, 2015.

13. Sinha G, Gupta S, Temkar S, Pandey V, Sihota R and Dada T: IOP agreement between I-Care TA01 rebound tonometer and the Goldmann applanation tonometer in eyes with and without glaucoma. Int Ophthalmol: Dec 16, 2014 (Epub ahead of print).

14. Farhood QK: Comparative evaluation of intraocular pressure with an air-puff tonometer versus a Goldmann applanation tonometer. Clin Ophthalmol 7: 23-27, 2013. 
15. Lee TE, Yoo C, Hwang JY, Lin S and Kim YY: Comparison of intraocular pressure measurements between Icare pro rebound tonometer and Tono-Pen XL tonometer in supine and lateral decubitus body positions. Curr Eye Res 40: 1-7, 2014.

16. Lee YK, Lee JY, Moon JI and Park MH: Effectiveness of the ICare rebound tonometer in patients with overestimated intraocular pressure due to tight orbit syndrome. Jpn J Ophthalmol 58: 496-502, 2014

17. Borrego Sanz L, Morales-Fernandez L, Martínez de-la-Casa JM, Sáenz-Francés F, Fuentes M, García-Feijóo J: The Icare-pro rebound tonometer versus the hand-held applanation tonometer in congenital glaucoma. J Glaucoma 25: 149-154, 2016.

18. Iliev ME, Goldblum D, Katsoulis K, Amstutz C and Frueh B: Comparison of rebound tonometry with Goldmann applanation tonometry and correlation with central corneal thickness. Br J Ophthalmol 90: 833-835, 2006.
19. Pakrou N, Gray T, Mills R, Landers J and Craig J: Clinical comparison of the Icare tonometer and Goldmann applanation tonometry. J Glaucoma 17: 43-47, 2008.

20. Martinez-de-la-Casa JM, Garcia-Feijoo J, Vico E, FernandezVidal A, Benitez del Castillo JM, Wasfi M and Garcia-Sanchez J: Effect of corneal thickness on dynamic contour, rebound, and goldmann tonometry. Ophthalmology 113: 2156-2162, 2006.

21. Liu J and Roberts CJ: Influence of corneal biomechanical properties on intraocular pressure measurement: quantitative analysis. J Cataract Refract Surg 31: 146-155, 2005.

22. Chui WS, Lam A, Chen D and Chiu R: The influence of corneal properties on rebound tonometry. Ophthalmology 115: 80-84,2008.

23. Moreno-Montañés J, García N, Fernández-Hortelano A and García-Layana A: Rebound tonometer compared with goldmann tonometer in normal and pathologic corneas. Cornea 26: 427-430, 2007. 